\title{
Patient-centered approaches to targeting incomplete bowel preparations for inpatient colonoscopies
}

\author{
Lindsey Russella,b, Pamela Mathuraa,c, Amanda Lee ${ }^{a}$, Raveena Dhaliwala , Narmin Kassamª, \\ Ali Kohansala,d
}

University of Alberta, Edmonton AB Canada; McMaster University, Hamilton ON Canada; Alberta Health Services, Edmonton AB Canada; Dalhousie University, Halifax NS, Canada

\section{Abstract}

\section{Introduction}

Poor-quality inpatient bowel preparation for colonoscopy has been well described and affects up to $50 \%$ of procedures [1].

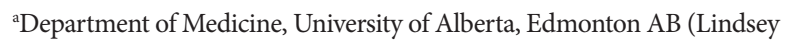
Russell, Pamela Mathura, Amanda Lee, Raveena Dhaliwal, Narmin Kassam, Ali Kohansal); ${ }^{\mathrm{b} M c M a s t e r ~ U n i v e r s i t y, ~ H a m i l t o n ~ O N ~(L i n d s e y ~}$

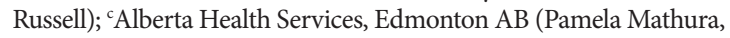
Narmin Kassam); ${ }^{\mathrm{d} D i v i s i o n}$ of Digestive Care and Endoscopy, Department of Medicine, Dalhousie University, Halifax NS (Ali Kohansal), Canada

Conflict of Interest: None

Correspondence to: Pamela Mathura, 8440112 St NW, Edmonton, AB T6G 2B7, Canada, e-mail: pam.mathura@albertahealthservices.ca

Received 9 November 2020; accepted 3 February 2021; published online 2 April 2021

DOI: https://doi.org/10.20524/aog.2021.0623
Incomplete bowel preparation may delay treatment decisions, decrease gastrointestinal (GI) pathology detection, and increase repeat procedures and cost [2,3]. Standardized orders for bowel preparation can help reduce poor preparation, as demonstrated in previous studies [1]. Patient education is a vital aspect of successful bowel preparation [4], as a recent study demonstrated improved bowel preparation scores after the implementation of an educational booklet [5]. Patients' experience is affected by the instructions and education around colonoscopies $[4,6]$.

The University of Alberta Hospital (UAH) has 2 GI inpatient units and the institutional standard colonoscopy preparation was $4 \mathrm{~L}$ of Golytely ${ }^{\circledR}$. However, recent data suggest that a 2-L split prep is superior to a 4-L one [7]. When we surveyed $20 \mathrm{GI}$ staff physicians, we found that only $45 \%$ of physicians ordered the 2-L split prep. In a randomized chart audit conducted from November 2018 to March 2019, we found that 34\% (44/128) of all inpatient bowel preparations were rated as poor and 14 
colonoscopies were repeated $(11 \% ; 14 / 128)$. The aim of this quality improvement (QI) project was to decrease the number of incomplete inpatient colonoscopies as a result of poor bowel preparations, and to improve patient preparation experience through simple and easy-to-use interventions.

\section{Materials and methods}

The Model for Improvement [8] and Donabedian [9] conceptual evaluation framework guided this project (Supplementary Fig. 1). We developed an interdisciplinary QI team that included GI/endoscopy unit managers, physicians, medical students, and a quality consultant. To identify improvement opportunities we completed QI tools, including direct observation, force-field and fishbone analysis (Supplementary Fig. 1), reviewed colonoscopy data, surveyed physicians and nurses, and completed a randomized chart audit on 129 charts from 2 GI units. This study was conducted in accordance with local organizational policies and formal Ethical Committee approval was not required [10].

Three improvement opportunities were identified: bowel preparation ordering, nursing education, and patient education (Supplementary Fig. 2). A bowel preparation order label for a 2-L split prep of Golytely ${ }^{\circledR}$ was created to promote order consistency to international standards [7]. A patient educational paper "placemat" was developed to facilitate standardized education about colonoscopy preparation, including a selftracking section with the paper placemat placed on the patient's bedside table during bowel preparation (Fig. 1). This tool was initially pilot tested with 6 patients and the feedback obtained was incorporated, resulting in a revised placemat. To support nursing education a "Nursing Tip" sheet was created to provide strategies for patients who were having difficulty consuming the preparation fluid (Fig. 2). The nursing tip sheet was designed with the help of 2 unit managers based on commonly reported issues. Plan-Do-Study-Act (PDSA) cycles were carried out to test and analyze the effect of the interventions. The outcome measure was a $30 \%$ reduction in incomplete inpatient colonoscopies. The process measures included the monthly number of colonoscopy order labels and placemats used. The balancing measure was the number of repeat colonoscopies. The SQUIRE 2.0 guideline framework was used to report findings for this project (Supplementary Table 1).

Data was collected for analysis through retrospective chart audits, nursing notes, and colonoscopy reports. In addition, surveys were developed on a 5-point Likert scale (Supplementary Fig. 3) and completed by patients, physicians and nurses to determine the feasibility and satisfaction of each intervention. Bowel preparation was determined by keywords in the procedure note and noted to be the overall bowel preparation quality as deemed by the endoscopist. Only procedures with clearly good or bad prep noted in the procedure note were included in the analysis.

\section{Statistical analysis}

Continuous variables were reported as median with interquartile ranges (IQR). Differences between pre- and post-intervention in the preparation quality for colonoscopies and the sex of inpatients were evaluated using Fischer's exact test. Age, Carlson comorbidity index score [11], and Schmid Fall Risk score [12] (Supplementary Table 2) were

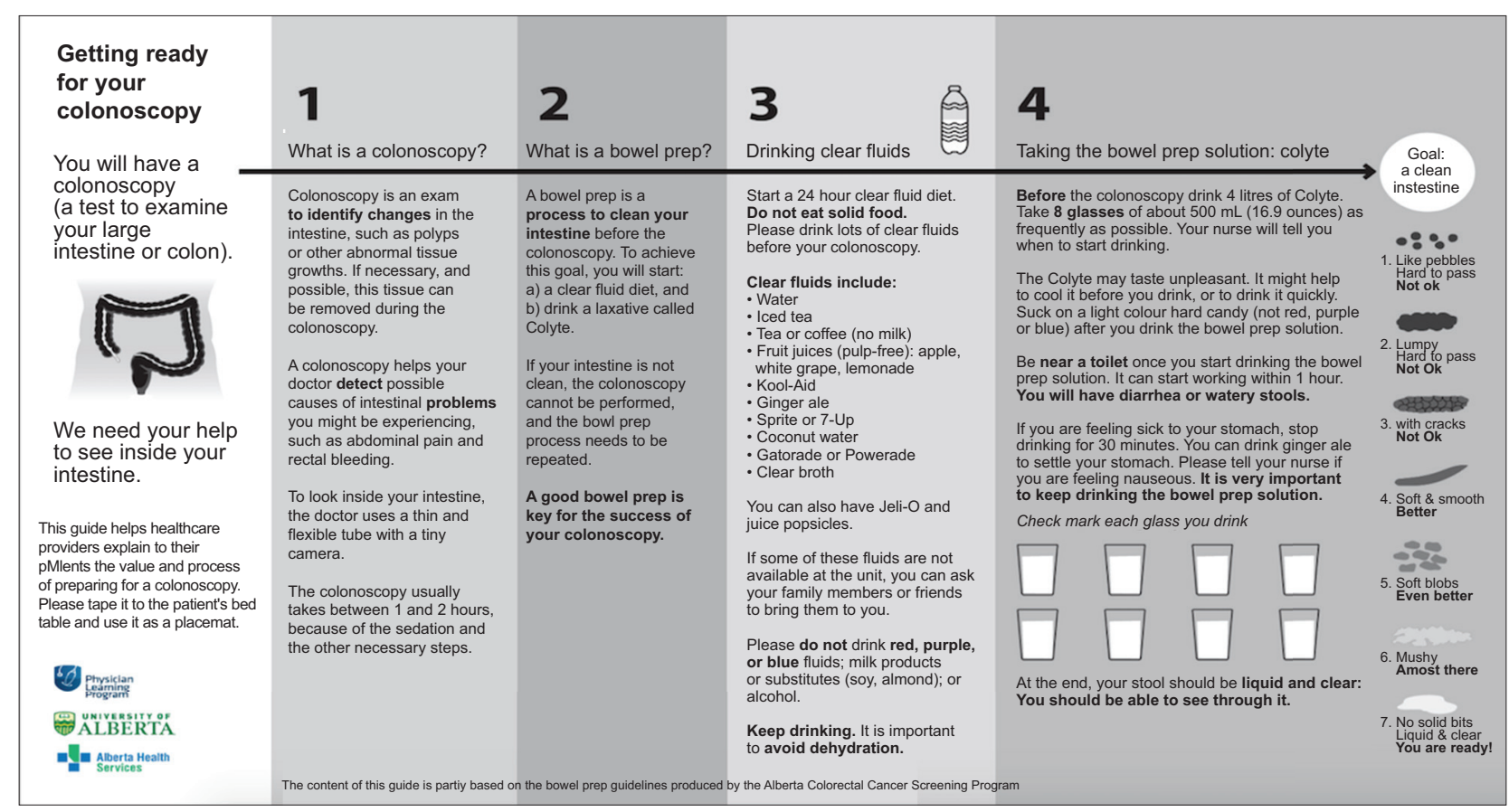

Figure 1 Patient education paper placemat, used to help educate patients and track bowel preparation 


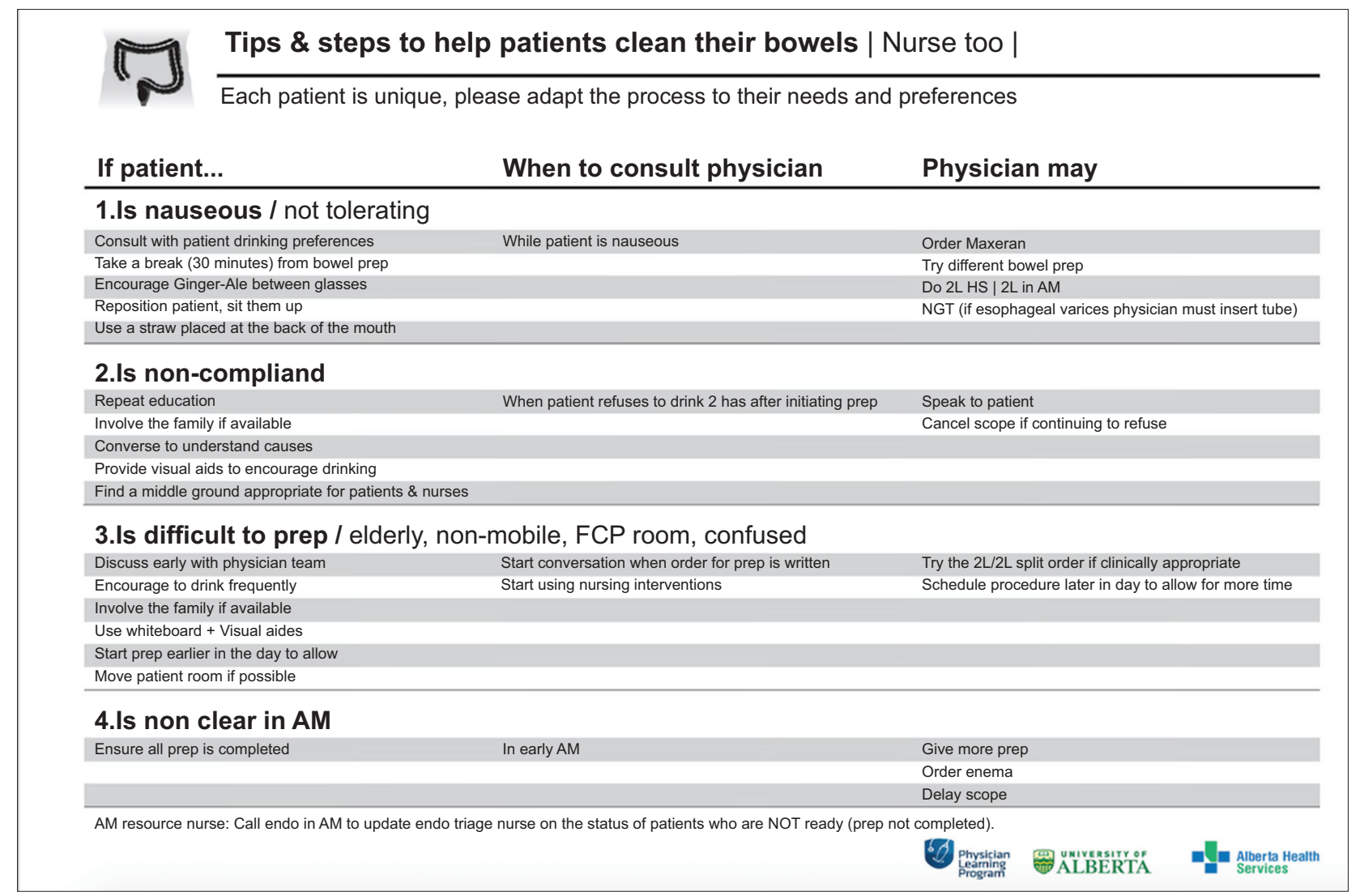

Figure 2 Educational tool for nurses to use when facing difficulties with patient bowel preparation

compared between poorly and well prepped patients in the post-intervention group using the Mann-Whitney $U$ test. All statistical analyses were conducted using IBM SPSS v26 (IBM Corp. Released 2019. IBM SPSS Statistics for MAC, Version 26.0. Armonk, NY: IBM Corp).

\section{Results}

A total of 128 colonoscopies were audited prior to intervention and 66 colonoscopies post intervention. After removal of those with no comments on colonoscopy prep on the procedure notes, 99 colonoscopies prior to intervention and 47 colonoscopies post intervention were analyzed. Prior to the intervention, 44\% (44/99) of inpatient colonoscopies reported poor prep, resulting in 10 repeat procedures $(10 \%$; 10/99). Of the repeated procedures, the most common indication for colonoscopy was lower GI bleeding (4/10) and the most common reason for repeated colonoscopy was poor prep (8/10 repeated procedures). The interventions did not have to be adjusted during the PDSA cycles. However, we did find that the standardized ordering label needed to be available in the Emergency Department for new GI admissions and we needed to provide education to rotating residents on the GI unit and new nursing staff during the study period of May 14-August 31, 2018.

Post intervention, approximately $60 \%(28 / 47)$ of the colonoscopies used the standardized order label and $66 \%$ $(31 / 47)$ of physician orders used the 2-L split prep. A total of $80 \%$ of patients were provided with the placemat at their bedside. Of the 47 colonoscopy reports audited post intervention, $27.7 \%$ (13/47) had poor bowel prep and $72.3 \%$ (34/47) had good prep (Table 1 ). There was a significant reduction in poor bowel preparation compared to pre intervention $(\mathrm{P}=0.038)$ (Table 1$)$.

As regards the balancing measure, there was a reduction in the number of repeat colonoscopies from $10 \%(10 / 99)$ to $4 \%(2 / 47)$. Notably, only $1 / 2$ repeated colonoscopies post intervention was due to poor prep, compared to $8 / 10$ of the repeated procedures prior to the intervention $(\mathrm{P}=0.27)$. Lower GI bleeding was the most common indication for colonoscopy in the patients who had poor preparation but did not have a repeat colonoscopy.

There was no significant difference in Charleston comorbidity index scores, age or Schmid Fall Risk scores between patients with good or poor bowel preparation or pre/ post intervention (Tables 1,2). However, on subgroup analysis comparing good and poor bowel preparation either pre or post PDSA intervention, there were significantly more men with poor preparation in the pre-PDSA group $(\mathrm{P}=0.029)$ and 
Table 1 Comparative variables between pre and post PDSA (Plan-Do-Study-Act) cycles. All continuous variables are reported as median with interquartile range (IQR)

\begin{tabular}{|c|c|c|c|}
\hline Variable & $\begin{array}{c}\text { Pre-PDSA } \\
\quad(\mathrm{N}=99)\end{array}$ & $\begin{array}{c}\text { Post-PDSA } \\
\quad(\mathrm{N}=47)\end{array}$ & P-value \\
\hline $\begin{array}{l}\text { Age } \\
\text { (IQR) }\end{array}$ & $\begin{array}{c}67 \\
(24.5)\end{array}$ & $\begin{array}{c}66 \\
(20)\end{array}$ & $0.811^{*}$ \\
\hline $\begin{array}{l}\text { Sex } \\
\text { Male } \\
\text { Female }\end{array}$ & $\begin{array}{l}56 \\
43\end{array}$ & $\begin{array}{l}23 \\
24\end{array}$ & $0.246^{\dagger}$ \\
\hline $\begin{array}{l}\text { Carlson Comorbidity } \\
\text { Index [11] } \\
\text { (IQR) }\end{array}$ & $\begin{array}{l}4 \\
(4)\end{array}$ & $\begin{array}{l}4 \\
(4)\end{array}$ & $0.465^{\ddagger}$ \\
\hline $\begin{array}{l}\text { Schmid Fall Risk [12] } \\
\text { (IQR) }\end{array}$ & $\begin{array}{c}0 \\
(2)\end{array}$ & $\begin{array}{c}0 \\
(1)\end{array}$ & $0.847^{\ddagger}$ \\
\hline $\begin{array}{l}\text { Bowel Prep } \\
\text { Good Prep } \\
\text { Poor Prep }\end{array}$ & $\begin{array}{l}55 \\
44\end{array}$ & $\begin{array}{l}34 \\
13\end{array}$ & $0.038^{*}$ \\
\hline
\end{tabular}

ॠStatistically significant. ${ }^{\dagger}$ Fisher's exact test. ${ }^{{ }^{*}}$ Mann-Whitney U test

Table 2 Comparison of variables between total patients with good prep and poor prep both pre- and post-intervention (total is 146 colonoscopies). All continuous variables are reported as median with interquartile range (IQR)

\begin{tabular}{lccc}
\hline Variable & $\begin{array}{c}\text { Good Prep } \\
(\mathrm{N}=89 / 146)\end{array}$ & $\begin{array}{c}\text { Poor Prep } \\
(\mathrm{N}=57 / 146)\end{array}$ & P-value \\
\hline Age & 64 & 70 & $0.058^{\ddagger}$ \\
(IQR) & $(27)$ & $(16)$ & \\
Sex & & & $0.106^{\dagger}$ \\
$\quad$ Male & 44 & 35 & \\
$\quad$ Female & 45 & 22 & \\
$\begin{array}{l}\text { Carlson Comorbidity } \\
\text { Index [11] }\end{array}$ & 4 & 4 & $0.257^{\ddagger}$ \\
(IQR) & $(5)$ & $(3)$ & \\
$\begin{array}{l}\text { Schmid Fall Risk [12] } \\
\text { (IQR) }\end{array}$ & 0 & 1 & $0.118^{\ddagger}$ \\
\hline
\end{tabular}

${ }^{\dagger}$ Fisher's exact test, ${ }^{\ddagger}$ Mann-Whitney U test significantly higher Schmid Fall Risk Score for patients with poor preparation in the post-PDSA group ( $\mathrm{P}=0.048$ ) (Table 3 ). A total of $59 \%$ of the surveyed patients found the placemat helpful, $100 \%$ of surveyed physicians indicated that they would use the standardized label, and $100 \%$ of surveyed nurses perceived the nursing tips sheet to be helpful.

\section{Discussion}

The patient-centered interventions described above significantly reduced the number of poor-quality colonoscopies and the number of repeated colonoscopies. Interestingly, other factors such as comorbidities, sex or age did not differ between colonoscopies with good or poor prep (Table 2). Empowering patients with easy-to-follow instructions improved the patient's experience during the bowel preparation process and many patients suggested that the use of the placemat would be helpful for future colonoscopies. Using a standardized prep order label with an option for a split preparation reduced physician order variability and promoted the use of superior bowel preparation [7]. This also increased the ordering of the international standard 2-L split prep by GI physicians (66\% vs. 45\%). Providing nurses with strategies to navigate preparation challenges and complications offered consistency in approaching education and management for bowel preparation.

Prior literature on optimizing colonoscopy preparation have highlighted patient education as a key and beneficial factor to support bowel preparation [5]. However, this study used a large booklet and an educational session, which was time-consuming and required greater effort to implement [5]. The point-of-care placemat used in our study was an easyto-read single page paper document, placed on the patient's bedside table, offering simplified information about the bowel preparation process. The advantage of this approach is that it allowed for patient self-tracking during bowel prep and it standardized the explanation/teaching between nurses and patients. The novel nursing tip sheet provided nurses with

Table 3 Comparison of variables between good and bad prep colonoscopies within pre and post PDSA (Plan-Do-Study-Act) cycles. All continuous variables are reported as median with interquartile range (IQR)

\begin{tabular}{|c|c|c|c|c|c|c|}
\hline \multirow[t]{2}{*}{ Variable } & \multicolumn{3}{|c|}{ Pre-PDSA } & \multicolumn{3}{|c|}{ Post-PDSA } \\
\hline & $\begin{array}{l}\text { Good Prep } \\
(\mathrm{N}=55 / 99)\end{array}$ & $\begin{array}{l}\text { Poor Prep } \\
(\mathrm{N}=44 / 99)\end{array}$ & Statistics & $\begin{array}{l}\text { Good Prep } \\
(\mathrm{N}=34 / 47)\end{array}$ & $\begin{array}{l}\text { Poor Prep } \\
(\mathrm{N}=13 / 47)\end{array}$ & P-value \\
\hline $\begin{array}{l}\text { Age } \\
\text { (IQR) }\end{array}$ & $\begin{array}{c}61 \\
(26.5)\end{array}$ & $\begin{array}{c}70.5 \\
(15.5)\end{array}$ & $0.081^{*}$ & $\begin{array}{c}64.5 \\
(20.75)\end{array}$ & $\begin{array}{c}68 \\
(21)\end{array}$ & $0.378^{*}$ \\
\hline $\begin{array}{l}\text { Sex } \\
\text { Male } \\
\text { Female }\end{array}$ & $\begin{array}{l}26 \\
29\end{array}$ & $\begin{array}{l}30 \\
14\end{array}$ & $0.029^{* \dagger}$ & $\begin{array}{l}18 \\
16\end{array}$ & $\begin{array}{l}5 \\
8\end{array}$ & $0.288^{\dagger}$ \\
\hline $\begin{array}{l}\text { Carlson Comorbidity } \\
\text { Index[11] } \\
\text { (IQR) }\end{array}$ & $\begin{array}{l}3 \\
(5)\end{array}$ & $\begin{array}{l}4.5 \\
(4)\end{array}$ & $0.132^{\ddagger}$ & $\begin{array}{l}4.5 \\
(4.5)\end{array}$ & $\begin{array}{l}4 \\
(4)\end{array}$ & $0.943^{*}$ \\
\hline $\begin{array}{l}\text { Schmid Fall Risk[12] } \\
\text { (IQR) }\end{array}$ & $\begin{array}{c}0 \\
(1)\end{array}$ & $\begin{array}{c}0 \\
(2)\end{array}$ & $0.509^{\ddagger}$ & $\begin{array}{c}0 \\
(1)\end{array}$ & $\begin{array}{c}1 \\
(3)\end{array}$ & $0.048^{\star \neq}$ \\
\hline
\end{tabular}

${ }^{\star}$ Statistically significant. ${ }^{\dagger}$ Fisher's exact test. ${ }^{\ddagger}$ Mann-Whitney U test 
management plans to help patients during the bowel prep process, as prior literature identified that poor and variable nursing education was independently associated with poor bowel preparation [13]. The split bowel preparation of $2 \mathrm{~L}$ is superior to the 4 - $\mathrm{L}$ prep, as outlined in a prior metaanalysis [7], and the increased use of the split prep with the standardized order sticker for physicians allowed for the optimized prep to be ordered more consistently.

We anticipate that these interventions can be easily adopted by other hospital units with less experience regarding colonoscopy bowel preparation. The placemat is easy to read for both patients and nursing staff, and is inexpensive to distribute. In addition, all prior literature on optimizing colonoscopy preparation has highlighted education as a key and beneficial factor to support bowel preparation.

Strengths of this project include the extensive preproject information gathered to contextualize the problem of poor bowel preparation through surveys and chart audits. In addition, using a multidisciplinary team of physicians, nursing staff, managers and a QI specialist allowed for various perspectives and experiential knowledge to be shared regarding inpatient bowel preparation. The patient educational placemat was easy to introduce and the financial cost of implementing this project was low. Finally, our target unit was the GI units, which have more patients requiring colonoscopy compared to other units, and where staff are already more knowledgeable about this procedure compared to other units, such as internal medicine or cardiology.

Study limitations included a non-validated survey, the absence of bowel preparation rating in some colonoscopy reports $(28.7 \%$ of the original cohort did not have comments on the prep post intervention and were excluded from analysis), and the lack of a pre-intervention patient satisfaction survey. In addition, while we noted whether the placemat was given or not, we did not evaluate any teaching the nurses provided around the placemat. Future studies will focus on the sustainability of the placemat for hospitalized patients, the nursing tip sheet as well as cost analysis. In addition, given the small sample size of this project, future studies with larger sample sizes would be worthwhile to validate these results.

Overall, by implementing these interventions targeting patient education, physician ordering and nursing management, we can improve both patient experience and health outcomes for the hospitalized patient population undergoing colonoscopy.

\section{Acknowledgments}

We would like to thank the University of Alberta Hospital and the University of Alberta Office of Lifelong Learning for the support of the development of the educational tools. In addition, we thank Dr. Mahmood Mohamed, Dr. Sander van Zanten, and the GI Unit Managers Hannah Rempel and Donna Perez for their help with conducting the project. This project was supported by the Alberta Health Services Quality Innovation Fund.

\section{Summary Box}

\section{What is already known:}

- Colonoscopy is essential for the diagnosis and treatment of ailments

- Proper inpatient colonoscopy preparation is difficult to obtain

- Patient-led education and standardized bowel preparation are key

\section{What the new findings are:}

- Poor colonoscopy preparation is independent of age, sex, comorbidities and mobility status

- Inpatient bowel preparation is improved by addressing concerns from physicians, patients and nurses

- An easily accessible placemat as an educational tool is a novel way to convey information to patients while they prep for a colonoscopy

\section{References}

1. Sullivan B, Zhang C, Wegermann K, Lee TH, Leiman DA. Standardizing inpatient colonoscopy preparations improves quality and provider satisfaction. Int J Health Care Qual Assur 2020;33:277-287.

2. Garber A, Sarvepalli S, Burke CA, et al. Modifiable factors associated with quality of bowel preparation among hospitalized patients undergoing colonoscopy. J Hosp Med 2019;14:278-283.

3. Hendry PO, Jenkins JT, Diament RH. The impact of poor bowel preparation on colonoscopy: a prospective single centre study of 10,571 colonoscopies. Colorectal Dis 2007;9:745-748.

4. Guo X, Yang Z, Zhao L, et al. Enhanced instructions improve the quality of bowel preparation for colonoscopy: a meta-analysis of randomized controlled trials. Gastrointest Endosc 2017;85:90-97.

5. Ergen WF, Pasricha T, Hubbard FJ, et al. Providing hospitalized patients with an educational booklet increases the quality of colonoscopy bowel preparation. Clin Gastroenterol Hepatol 2016;14:858-864.

6. Restall G, Michaud V, Walker JR, et al. Patient experiences with colonoscopy: a qualitiative study. J Can Assoc Gastroenterol 2019;3:249-256.

7. Martel M, Barkun AN, Menard C, Restellini S, Kherad O, Vanasse A. Split-dose preparations are superior to day-before bowel cleansing regimens: a meta-analysis. Gastroenterology 2015;149:79-88.

8. Langley GL, Moen R, Nolan KM, Nolan TW, Norman CL, Provost LP. The improvement guide: a practical approach to enhancing organizational performance. 2nd Edition. San Francisco, California, USA: Jossey-Bass Publishers; 2009.

9. Donabedian A, Wheeler JR, Wyszewianski L. Quality, cost, and health: an integrative model. Med Care 1982;20:975-992.

10. Hagen B, O’Beirne M, Desai S, Stingl M, Pachnowski CA, Hayward $S$. Innovations in the ethical review of health-related quality improvement and research: The Alberta Research Ethics Community Consensus Initiative (ARECCI). Healthc Policy 2007;2:e164-e177.

11. Charlson M, Szatrowski TP, Peterson J, Gold J. Validation of a combined comorbidity index. J Clin Epidemiol 1994;47:1245-1251.

12. Schmid NA. 1989 federal nursing service award winner. Reducing patient falls: a research-based comprehensive fall prevention program. Mil Med 1990;155:202-207.

13. Lee YJ, Kim ES, Park KS, et al. Education for ward nurses influences the quality of inpatient's bowel preparation for colonoscopy. Medicine (Baltimore) 2015;94:e1423. 


\section{Supplementary material}

Supplementary Table 1 Squires 2.0 Checklist

Title and Abstract

\begin{tabular}{ll}
\hline 1. Title & Patient-Centered Approaches to Targeting Incomplete Bowel Preparations for Inpatient Colonoscopies \\
2. Abstract & Background: A high-quality colonoscopy bowel prep is vital to completing the procedure. Adequate inpatient bowel \\
preparation has been consistently difficult to achieve because of multiple factors. Incomplete bowel prep can lead to \\
repeated colonoscopies, poor patient experience, increased costs, and prolonged hospitalization. This study aimed to \\
develop patient-centered interventions to optimize bowel prep for inpatients undergoing colonoscopy \\
Methods: The Model for Improvement and Donabedian frameworks guided this project. An interdisciplinary team \\
compiled quality improvement tools that identified areas for improvement. Interventions development included \\
a nursing tip sheet for troubleshooting symptoms, a standardized order label and a patient educational placemat. \\
Plan-Do-Study-Act (PDSA) cycles were carried out to test and analyze the effects of the interventions. The project aim was \\
a $30 \%$ reduction in incomplete inpatient colonoscopies from poor bowel prep. Process measures included the number of \\
colonoscopy split prep order labels, and placemats used. The balancing measure was the number of repeat colonoscopies. \\
Results: Prior to the intervention, $44 \%$ (44/99) of inpatient colonoscopies had poor bowel prep resulting in 10 repeat \\
procedures (10\%). Post intervention, $60 \%$ (28/47) of the colonoscopies used the standardized label, $66 \%$ of physician \\
orders used 2-L split prep, and $80 \%$ of patients were provided with the educational placemat. Of the 47 colonoscopies \\
audited post intervention, there was a significant decrease in poor prep (27.7\% [13/47], P=0.038) for colonoscopies. The \\
percentage of repeated colonoscopies decreased to $4 \%$ (2/47). \\
Conclusion: Developing simple and easy-to-use patient-centered interventions can effectively improve colonoscopy \\
preparation for hospitalized patients.
\end{tabular}

Introduction

3. Problem In a randomized chart audit conducted from November 2018 to March 2019, we found that 34\% (44/128) of all inpatient

Description bowel preparations were rated as poor and 14 colonoscopies were repeated (11\%; 14/128).

4. Available

Knowledge

5. Rationale

Poor-quality inpatient bowel preparation for colonoscopy has been well described and occurs in up to $50 \%$ of procedures
multidisciplinary team, and mapping we found three areas for improvement. Through surveys of physicians, nurses and multidisciplinary team, and mapping we found three areas for improvement. Through surveys of physicians, nurses and
patients and using outpatient colonoscopy booklets we created the three interventions for ease of education delivery and reassurance of proper split prep to be ordered.

6. Specific Aims The aim of this quality improvement (QI) project was to decrease the number of incomplete inpatient colonoscopies as a result of poor bowel preparations, and to improve patient preparation experience through simple and easy-to-use interventions.

Methods

7. Context The ward targeted was the GI ward, where they are used to prepping patients for colonoscopy. Moreover, chart review and mapping found areas specific to the UAH where areas could be improved upon.

8. Interventions -A bowel preparation order label for a $2 \mathrm{~L}$ split prep of Golytely ${ }^{\mathbb{B}}$ was created to promote order consistency to international standards.

-A patient educational paper "placemat" was developed to facilitate standardized education about colonoscopy preparation, including a self-tracking section with the paper placemat placed on the patient's bedside table during bowel preparation. This tool was initially pilot tested with 6 patients and the feedback obtained was incorporated, resulting in a revised placemat.

-To support nursing education a "Nursing Tip" sheet was created to provide strategies for patients who were having difficulty consuming the preparation fluid [Figure 2]. Two unit managers helped design the nursing tip sheet based on issues that nurses commonly reported.

9. Study of the Interventions Plan-Do-Study-Act cycles were carried out to test and analyze the effect of the interventions. Surveys pre- and post-intervention were used to assess the attitudes of stakeholders.

10. Measures The outcome measure was a 30\% reduction in incomplete inpatient colonoscopies. The process measures included the monthly number of colonoscopy order labels and placemats used. The balancing measure was the number of repeated colonoscopies.

11. Analysis Data were collected for analysis through retrospective chart audits, nursing notes, and colonoscopy reports. In addition, surveys were developed on a 5-point Likert scale and completed by patients, physicians and nurses to determine the feasibility and satisfaction of each intervention. Differences between pre- and post-intervention in the quality of preparation for colonoscopies were compared by Fischer's Exact Test. Charleston Comorbidity Index score and Schmid Fall Risk score between poor and well prepped patients in the post intervention group were compared using the MannWhitney U Test. All statistical analysis was conducted with IBM SPSS v26. 
Supplementary Table 1 (Continued)

Title and Abstract

\begin{tabular}{|c|c|}
\hline $\begin{array}{l}\text { 12. Ethical } \\
\text { Considerations }\end{array}$ & $\begin{array}{l}\text { We completed the ARECCI ethics screening tool and the score was "minimal risk"; thus, no formal ethics board review } \\
\text { was required as per local organizational policies. }\end{array}$ \\
\hline \multicolumn{2}{|l|}{ Results } \\
\hline 13. Results & 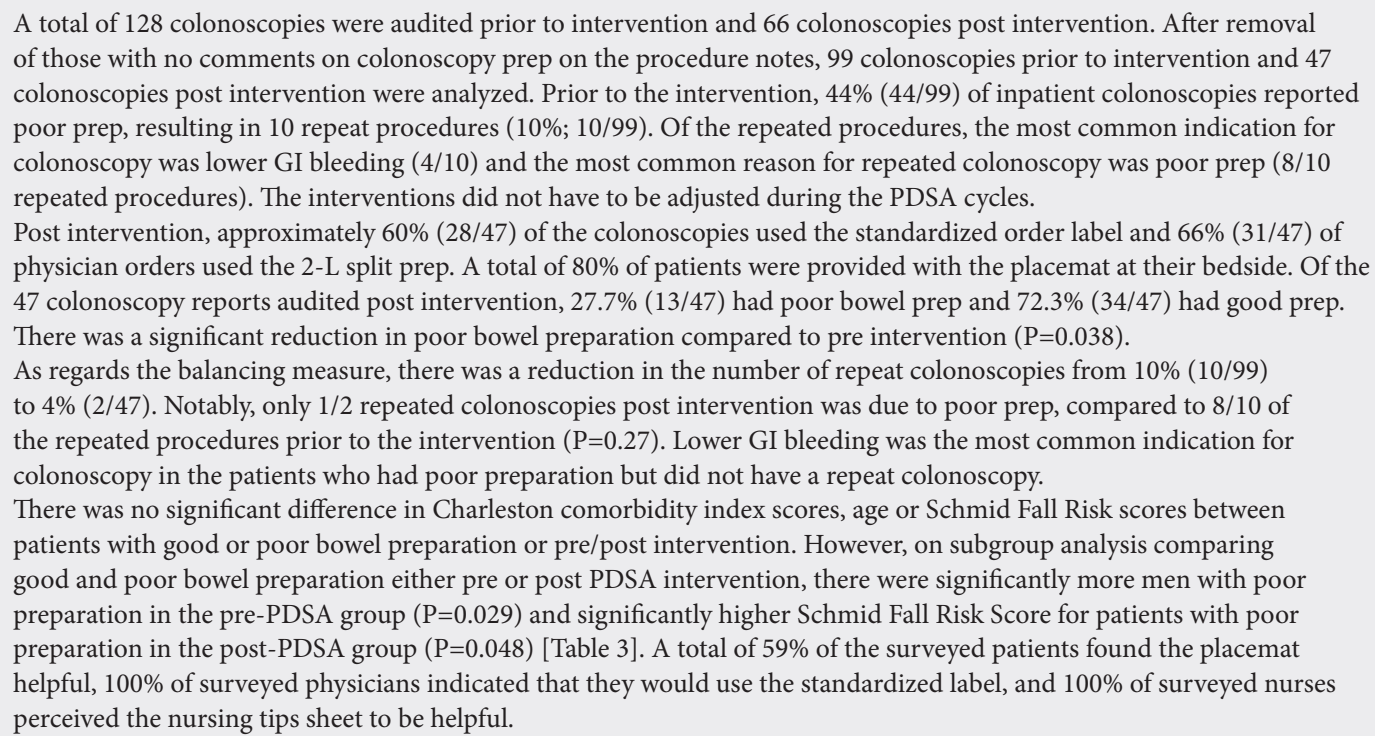 \\
\hline \multicolumn{2}{|l|}{ Discussion } \\
\hline 14. Summary & $\begin{array}{l}\text { The introduction of standardized label, nursing tip sheet and patient educational placemat led to a significant decrease in } \\
\text { poorly prepared colonoscopies. } \\
\text { Strengths of this project include the extensive pre-project information gathering to contextualize the problem of poor } \\
\text { bowel preparation through surveys and chart audits. In addition, using a multidisciplinary team of physicians, nursing } \\
\text { staff, managers and a QI specialist allowed for various perspectives and experiential knowledge to be shared regarding } \\
\text { inpatient bowel preparation. In addition, our target unit was the GI unit, which has more patients who require colonoscopy } \\
\text { compared to other units, and where staff are more knowledgeable about this procedure than those in other units, such as } \\
\text { internal medicine or cardiology }\end{array}$ \\
\hline 15. Interpretation & $\begin{array}{l}\text { Implementing patient-centered education tools led to a decrease in colonoscopies with poor prep. Similar results have been } \\
\text { reported with other educational tools. }\end{array}$ \\
\hline 16. Limitations & $\begin{array}{l}\text { Study limitations included a non-validated survey, the absence of bowel preparation rating in the colonoscopy reports, as } \\
27 \% \text { did not comment on the prep, and the lack of a pre-intervention patient satisfaction survey. In addition, we measured } \\
\text { whether the placemat was given or not and surveyed whether patients found it helpful; however, we did not evaluate any } \\
\text { teaching the nurses provided around the placemat }\end{array}$ \\
\hline 17. Conclusions & $\begin{array}{l}\text { Future studies will focus on the sustainability of the placemat for hospitalized patients, the nursing tip sheet, as well as } \\
\text { cost analysis. The UAH will implement an electronic medical record, therefore the bowel preparation physician order will } \\
\text { become automated and standardized at the } 2 \mathrm{~L} \text { split prep. } \\
\text { We anticipate that these interventions can be easily adopted by other hospital units with less experience regarding } \\
\text { colonoscopy bowel preparation. The placemat is easy to read for both patients and nursing staff and is inexpensive to } \\
\text { distribute. In addition, prior literature on optimizing colonoscopy preparation has all highlighted education as a key } \\
\text { and beneficial factor to support bowel preparation. By implementing these interventions, we can improve both patient } \\
\text { experience and health outcomes for the hospitalized patient population undergoing colonoscopy. }\end{array}$ \\
\hline \multicolumn{2}{|l|}{ Other Information } \\
\hline 18. Funding & This work was supported by Alberta Health Services Quality Innovation Fund \\
\hline
\end{tabular}


Supplementary Table 2 Carlson Comorbidity score [10] and Schmid Fall risk score [11]

\begin{tabular}{|c|c|c|}
\hline Score & $\begin{array}{l}\text { Carlson } \\
\text { Comorbidity Score }\end{array}$ & $\begin{array}{l}\text { Schmid Fall Risk } \\
\text { Score }\end{array}$ \\
\hline Components & $\begin{array}{l}\text { Age- } \\
\text {-50-59 (1) } \\
\text {-60-69 (2) } \\
\text {-70-79 (3) } \\
\text {->80 (4) } \\
\text { 1- } \\
\text {-Myocardial } \\
\text { infarction } \\
\text {-Congestive heart } \\
\text { failure } \\
\text {-Peripheral vascular } \\
\text { disease } \\
\text {-Dementia } \\
\text {-Cerebrovascular } \\
\text { disease } \\
\text {-Chronic lung } \\
\text { disease } \\
\text {-Connective tissue } \\
\text { disease } \\
\text {-Ulcer } \\
\text {-Chronic liver } \\
\text { disease } \\
\text { 2- } \\
\text {-Hemiplegia } \\
\text {-Moderate/severe } \\
\text { kidney disease } \\
\text {-Diabetes } \\
\text {-Diabetes with } \\
\text { complications } \\
\text {-Tumor } \\
\text {-Leukemia } \\
\text {-Lymphoma } \\
\text { 3- } \\
\text { Moderate or severe } \\
\text { liver disease } \\
\text { 6- } \\
\text {-Malignant tumor } \\
\text {-Metastasis } \\
\text {-AIDS }\end{array}$ & $\begin{array}{l}\text { Mobility } \\
\text {-Ambulates with no } \\
\text { gait disturbance (0) } \\
\text {-Ambulated or } \\
\text { transfers with } \\
\text { assistive devises (1) } \\
\text {-Ambulated with } \\
\text { unsteady gait and no } \\
\text { assistance (1) } \\
\text {-Unable to ambulate } \\
\text { or transfer (0) } \\
\text { Mentation } \\
\text {-Alert, orientated } \\
\text { X3 (0) } \\
\text {-Periodic } \\
\text { confusion (1) } \\
\text {-Confusion at all } \\
\text { times (1) } \\
\text {-Comatose/ } \\
\text { unresponsive (0) } \\
\text { Elimination } \\
\text {-Independent in } \\
\text { elimination (0) } \\
\text {-Independent } \\
\text { with frequency or } \\
\text { diarrhea (1) } \\
\text {-Needs assistance } \\
\text { with toileting (1) } \\
\text {-Incontinence (1) } \\
\text { Prior Fall } \\
\text { History (within } \\
\text { 6months) } \\
\text {-Yes (before } \\
\text { admission) (1) } \\
\text {-Yes (During } \\
\text { admission) (2) } \\
\text {-No (0) } \\
\text {-Unknown (0) }\end{array}$ \\
\hline Interpretation & $\begin{array}{l}\text { Higher score } \\
\text { equates to higher } \\
\text { estimated } 10 \text {-year } \\
\text { mortality }\end{array}$ & $\begin{array}{l}\text { Score } 3 \text { or more: } \\
\text { Patient at risk } \\
\text { for falls and } \\
\text { fall prevention } \\
\text { interventions should } \\
\text { be implemented }\end{array}$ \\
\hline
\end{tabular}




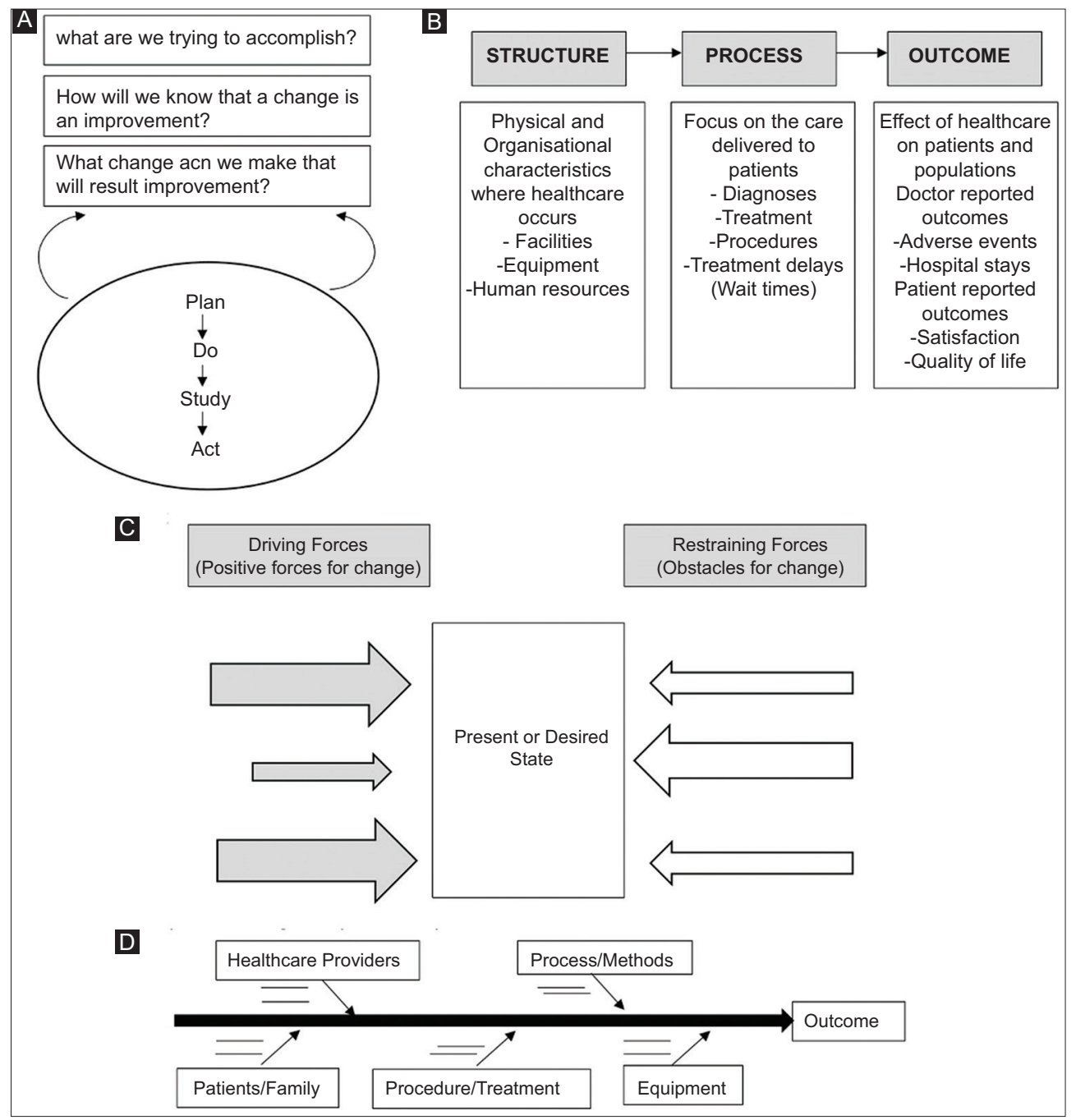

Supplementary Figure 1 (A) Model for improvement- Adapted from Langley et al [8]. (B) Donabedian's framework for health care improvement- Adapted from Donabedian, A [9]. (C) Force field analysis indicating driving and restraining forces contributing to present or desired state. The size of the arrow for a specific force indicates the strength of that force's contribution. (D) Fishbone analysis provides a pictorial view of the key stakeholders, equipment and process measures that contribute to an outcome of interest. The goal of fishbone analysis is to identify areas to target for possible improvement 


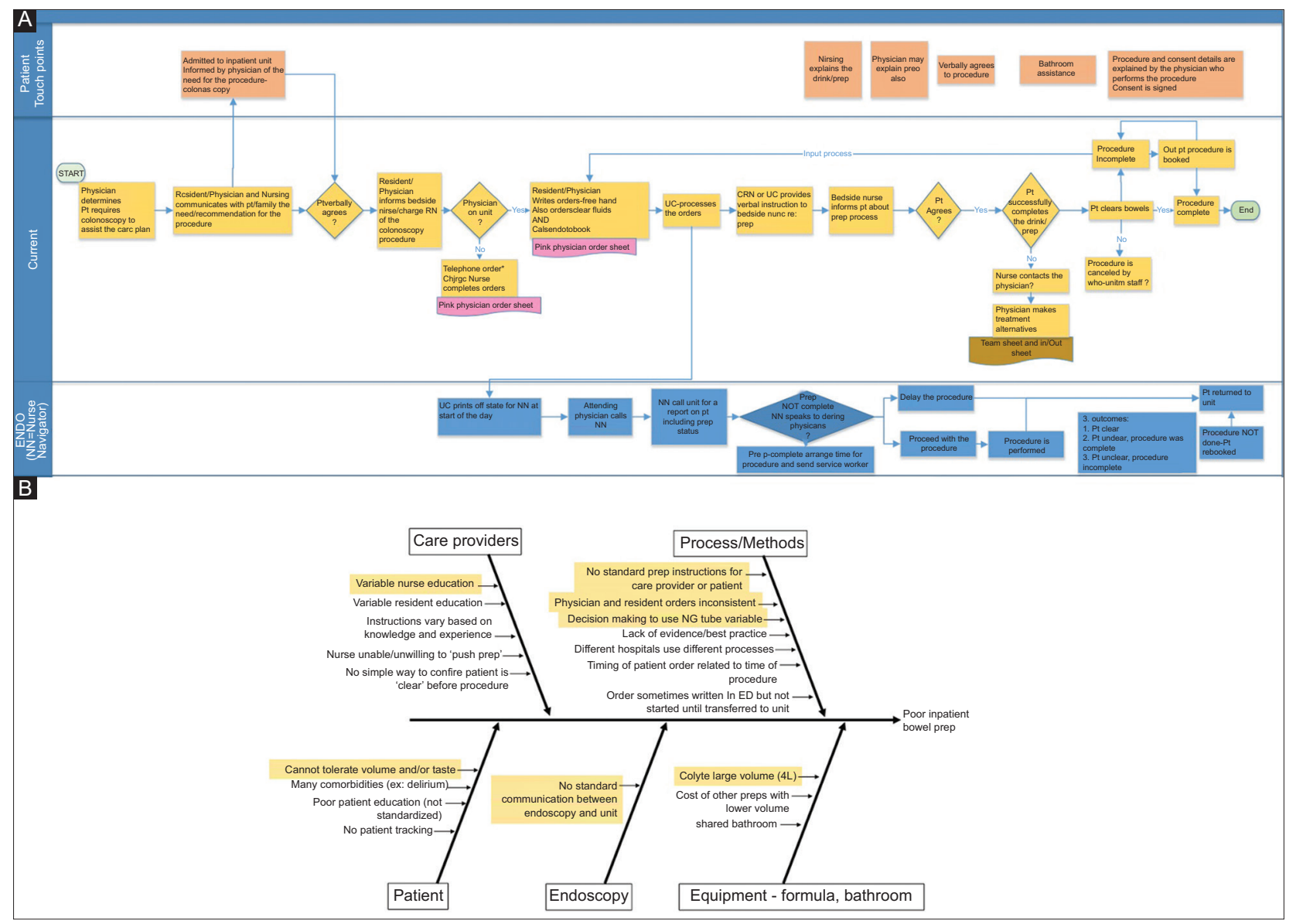

Supplementary Figure 2 (A) Process mapping of inpatient colonoscopy prep for this project. (B) Fishbone analysis of this project 


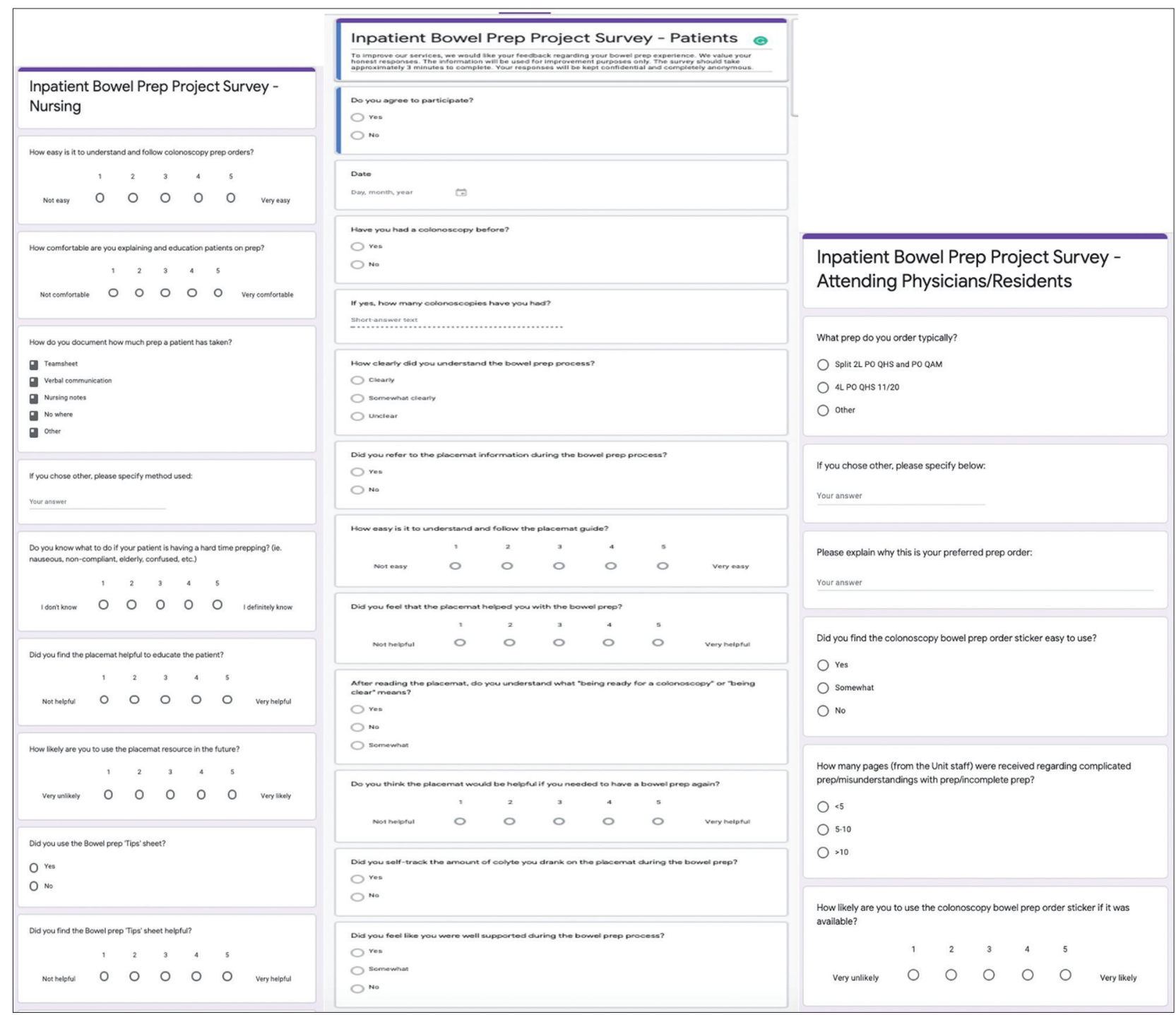

Supplementary Figure 3 Surveys used for physicians/residents, nursing staff, and patients 